\title{
O CONTEXTO ECONÔMICO DAS MPE E A INFLUÊNCIA DA ESTRUTURA ORGANIZACIONAL NO PROCESSO DE INOVAÇÃO: ESTUDO REALIZADO COM PEQUENAS EMPRESAS DA REGIÃO DE SÃO SEBASTIÃO - DF
}

\section{ARTIGO ORIGINAL}

GOMES, Mislene Rodrigues de Aguiar ${ }^{1}$

GUIMARÃES, Arthur Oscar ${ }^{2}$

GOMES, Mislene Rodrigues de Aguiar. GUIMARÃES, Arthur Oscar. O contexto econômico das MPE e a influência da estrutura organizacional no processo de inovação: estudo realizado com pequenas empresas da região de São Sebastião - DF. Revista Científica Multidisciplinar Núcleo do Conhecimento. Ano 05, Ed. 04, Vol. 06, pp. 27-40. Abril de 2020. ISSN: 2448-0959, Link de acesso: https://www.nucleodoconhecimento.com.br/administracao/contexto-economico-dasmpe, DOI: 10.32749/nucleodoconhecimento.com.br/administracao/contextoeconomico

\section{RESUMO}

Este trabalho descreve como a estrutura administrativa influencia o processo de inovação da empresa, e busca responder qual a relação entre os tipos de estruturas existentes e o grau de inovação dessas empresas. O objeto de estudo foi uma amostra de 28 micro e pequenas empresas do segmento de comércio da Região de São Sebastião-DF, que no período de 2015 a 2017 participaram do programa ALI. Os dados foram coletados no Diagnóstico MPE e no Radar de Inovação, e a análise

\footnotetext{
${ }^{1}$ Pós-Graduada em Administração Financeira e em Administração de Empresas, Graduação em Administração.

${ }^{2}$ Graduação em Ciências Econômicas. Mestrado em Engenharia de Produção. Doutorado em Sociologia.
} 
realizada concentrou-se na dimensão, organização, relacionando-a ao Grau de inovação Geral e ao Desempenho Geral Administrativo. Os resultados alcançados demonstraram que a estrutura organizacional influencia o grau de inovação, tendo diferenciação entre o tipo de estrutura adotado, de considerando as relações internas, processos e organização do trabalho e, as relações externas com o mercado, parcerias e estratégias competitivas com as inovações geradas pela empresa.

Palavras-chave: Estrutura Organizacional, inovação, Gestão Administrativa.

\section{INTRODUÇÃO}

As mudanças constantes no mercado empresarial impulsionam a competição entre as empresas. Diante de um cenário em que a inovação ocupa papel fundamental, as empresas precisam, cada vez mais, serem flexíveis e se adequarem às necessidades dos consumidores.

O modelo de estrutura organizacional adotado por cada uma das empresas define sua forma de trabalhar frente ao mercado, suas relações internas e externas e a coordenação dessas atividades frente ao objetivo empresarial comum. De acordo com Tidd, et al (2008), a inovação torna-se cada vez mais uma tarefa ampla, que envolve as áreas de produção, marketing, administração e compras, o que direciona a empresa a uma mudança organizacional que reflete diretamente na sua estrutura administrativa, obtendo resultados proporcionais a sua rigidez estrutural.

Nesse sentido, a pesquisa realizada objetivou analisar a influência da inovação na estrutura organizacional e a sua flexibilidade de adaptação ao mercado. A pesquisa analisou 28 empresas do comércio da cidade de São Sebastião-DF, participantes do programa ALI- DF, no período de 2015 a 2017.

A metodologia utilizada para a coleta de dados da amostra é classificada como uma pesquisa exploratória e quantitativa. As bases de dados utilizadas para a pesquisa foram o Diagnóstico Empresarial de Gestão e o Radar de Inovação, ambos do 
Programa ALI, compostos de questões fechadas que permitem a análise quantitativa dos dados.

No âmbito do Programa ALI, a pesquisa de campo ocorreu no período de Outubro/2015 a Abril/2017, realizada in loco, com a presença do empresário e/ou responsável pela empresa.

O diagnóstico empresarial avalia a gestão das empresas. Trata-se de um questionário de auto avaliação utilizado pela FNQ (Fundação Nacional da Qualidade), adaptado pelo SEBRAE e pelo CNPq, no Programa Agentes Locais de Inovação. O Radar de Inovação, por sua vez, consiste em uma ferramenta de avaliação da inovação nas empresas. Elaborado pelo Sebrae, utiliza metodologia que, além do resultado global, fornece dados relativos a 13 dimensões diferentes, particularmente em relação às inovações realizadas.

Este trabalho está divido em 5 partes: a primeira compreende a introdução na qual se contextualiza o tema; a segunda menciona estudos relacionados ao objetivo desse artigo científico; a terceira expõe os resultados aferidos pelas empresas participantes do programa ALI; a quarta parte traz a conclusão e as últimas considerações do presente estudo, e por fim, as referências bibliográficas utilizadas na elaboração desse estudo.

\section{QUADRO GERAL DAS MICRO E PEQUENAS EMPRESAS DO PAÍS}

As micro e pequenas empresas (MPE) têm considerável representatividade no produto interno bruto brasileiro (PIB) do País. Segundo dados do Sebrae em parceria com a FGV ${ }^{[3]}$, essa participação chega a $27 \%$, com crescimento nos últimos anos. $\mathrm{O}$ crescimento e a abertura constante de pequenos negócios têm sido identificados como uma grande onda de empreendedorismo no país. De acordo com a pesquisa GEM $2015^{[4]}$, a maior taxa de empreendedorismo da série histórica foi atingida pelo país. Em cada 10 brasileiros, em torno de 4 iniciaram um negócio ou implementaram uma ação visando a criação de um novo negócio. Essa onda pode ser considerada como reflexo natural da atual situação econômica do país, em que a opção por iniciar 
um empreendimento se torna uma alternativa de trabalho e renda para muitos brasileiros em meio à crise.

As empresas analisadas no âmbito desse artigo apresentam uma maioria formada por famílias e jovens em busca da realização de sonhos, universo no qual há grande diversidade nos padrões de experiência e formação profissional e empresarial. Sendo este fator preponderante na estruturação dessas empresas, muitas vezes iniciadas na informalidade, com alta centralização de atividades nas mãos dos proprietários, sem padrões de processos e responsáveis definidos, e praticamente sem registro e mensuração dos resultados.

\subsection{ESTRUTURA ORGANIZACIONAL E MODELOS DE GESTÃO PARA INOVAÇÃO}

Há que considerar nesse debate o alcance dos conceitos e aspectos relacionados à estrutura organizacional e aos modelos de gestão. De acordo com Oliveira (2006, p.54):

... a estrutura organizacional é o instrumento administrativo resultante da identificação, análise, ordenação e agrupamento das atividades e dos recursos das empresas, incluindo o estabelecimento dos níveis de alçada e dos processos decisórios, visando ao alcance dos objetivos estabelecidos pelos planejamentos das empresas.

A diferenciação dos tipos de estrutura encontra-se baseada, principalmente, nas relações observadas a partir do organograma empresarial, podendo ser verticalizadas ou horizontalizadas. O modelo vertical se baseia principalmente na estrutura hierárquica ou piramidal, com postos de trabalho agrupados por departamentos e funções numa linha de hierarquia em que os níveis dependem do tamanho da organização. Para Brews e Toucci (2004) esse agrupamento tem como vantagem permitir a eficiência e promover o desenvolvimento e uma maior especialização. Já para Hansen e Nohria (2004) existe a desvantagem de pessoas com as mesmas 
habilidades e conhecimentos desenvolverem uma visão simplista dos departamentos e ter dificuldade em apreciar outra visão do que é importante para a organização.

A descrição acima parece estar bastante distante da realidade constatada na amostra aqui analisada. Antes de considerar suas especificidades, cumpre considerar que na estrutura horizontalizada, segundo Ostroff (1999), há a redução de níveis hierárquicos resultando na eliminação de trabalhos que agregam valor e a transferência de responsabilidades gerenciais, permitindo uma autonomia de decisão sobre suas atividades dentro do processo como um todo. Sua principal característica é a alta comunicação entre todos os agentes e a priorização pela agilidade do trabalho. Para Mengue e Auh (2009) as organizações horizontais promovem a maior participação das pessoas na obtenção dos objetivos organizacionais, aproveitando de forma mais efetiva a capacidade e as habilidades de todos os envolvidos no processo, fomentando as inovações.

Estudar a estrutura das empresas é fundamental para identificar a forma de relacionamento interno, como ocorre a execução das atividades, a relação entre insumos e produtos e, principalmente, permite verificar as estratégias tomadas pela empresa frente ao mercado. Ozsomer, Calantone e Di Benedetto (1997) ressaltam que a estrutura organizacional influencia diretamente a postura estratégica da empresa, sendo este um fator importante, que pode aumentar o que os autores denominam de inovatividade. A estrutura organizacional da empresa pode influenciar diretamente no desenvolvimento das inovações, é a constatação de Menguc e Auh (2009).

Por seu turno, cumpre ainda entender e analisar o ambiente externo, que é fundamental para o gestor da empresa, pois quando a estrutura e suas estratégias estão diretamente ligadas às tendências do mercado, a inovação tende a fazer parte do cotidiano da empresa. Para se entender a influência da estrutura na performance inovativa deve-se compreender a complexidade intrínseca das organizações que inovam. Estamos diante de um processo em que se constata, mesmo sabendo-se das dificuldades culturais a serem enfrentadas, a necessidade real de distribuir as responsabilidades para as equipes em meio à gama de diferentes níveis de 
especialização e horizontes de tempo (THAMHAIN, 2003; BROWN; EISENHART, 1995, apud Negano et al ( 2014).

De acordo com Marx (1997) as adaptações das estruturas organizacionais refletem um impacto sensível na forma pela qual o trabalho é organizado. Essa forma de entender o processo se alia às reflexões de Neto e Filho (2000), que afirmam ser a flexibilidade organizacional à capacidade de reação da organização frente aos sobressaltos impostos pelos movimentos de inovação, visto representarem umas das vantagens competitivas na concorrência do mercado.

\subsection{ANÁLISE DOS DADOS}

Com base nas referências teóricas apresentadas, o objetivo do artigo é identificar a influência da estrutura adotada pela empresa sobre o processo de inovação. Para tal, foram analisados os seguintes fatores: Dimensão Organização e Grau de Inovação Geral presentes no Radar de Inovação, do Programa ALI, buscando identificar a representatividade dessa dimensão no grau de inovação geral da empresa. Em boa medida, as análises permitiram verificar a maturidade de gestão administrativa dessas empresas.

A análise e cruzamento desses dados são importantes para observar a relação entre gestão e inovação, mas principalmente a influência que uma tem sobre a outra e a relação de conectividade entre os dois aspectos, observando-se o comportamento da empresa frente a inovação e sua adaptabilidade.

O perfil das empresas em estudo corresponde exclusivamente ao setor de comércio, sendo um total de $28 \mathrm{MPE}$ atuantes em diversos segmentos, concentradas nas áreas de moda, material para construção, papelaria e alimentação. (Ver Quadro 1)

Quadro 1- Número de empresas por segmento de mercado

Segmento de Mercado

Moda 


\begin{tabular}{|l|l|}
\hline Material para Construção & 6 \\
\hline Papelaria & 5 \\
\hline Alimentação & 5 \\
\hline Farmácia & 3 \\
\hline Cosméticos & 1 \\
\hline Acessórios Automotivos & 1 \\
\hline Total & $\mathbf{2 8}$ \\
\hline
\end{tabular}

Fonte: elaborado pelo próprio autor.

Em relação aos dados coletados, obteve-se 12,70 como média dos dados valor correspondente ao Desempenho de Gestão das empresas. Esse desempenho é o resultado numa escala que varia de 0 a 100, utilizada para medir o nível de maturidade administrativa na gestão de pessoas, processos, clientes e resultados. Portanto, esse valor de 12,70 demonstra a baixa maturidade das empresas no que diz respeito ao aspecto de gestão administrativa do negócio.

A dimensão organização e o grau de inovação geral, avaliados por meio dos dados pesquisados no Radar de Inovação, apresentaram médias de 1,4 e 1,48 respectivamente.[5]

Quadro 2 - Média dos dados coletados.

\begin{tabular}{|l|l|l|l|}
\hline \multicolumn{2}{|l}{ Média dos Dados } & Coletados & \\
Empresas & Desempenho de & Dimensão & Grau de inovação \\
comércio & gestão & Organização & Geral \\
\hline Média geral & $\mathbf{1 2 , 7 0}$ & $\mathbf{1 , 4 0}$ & $\mathbf{1 , 4 8}$ \\
\hline
\end{tabular}

Fonte: Elaborado pelo próprio autor. 
Gráfico 1 - Relação entre os dados.

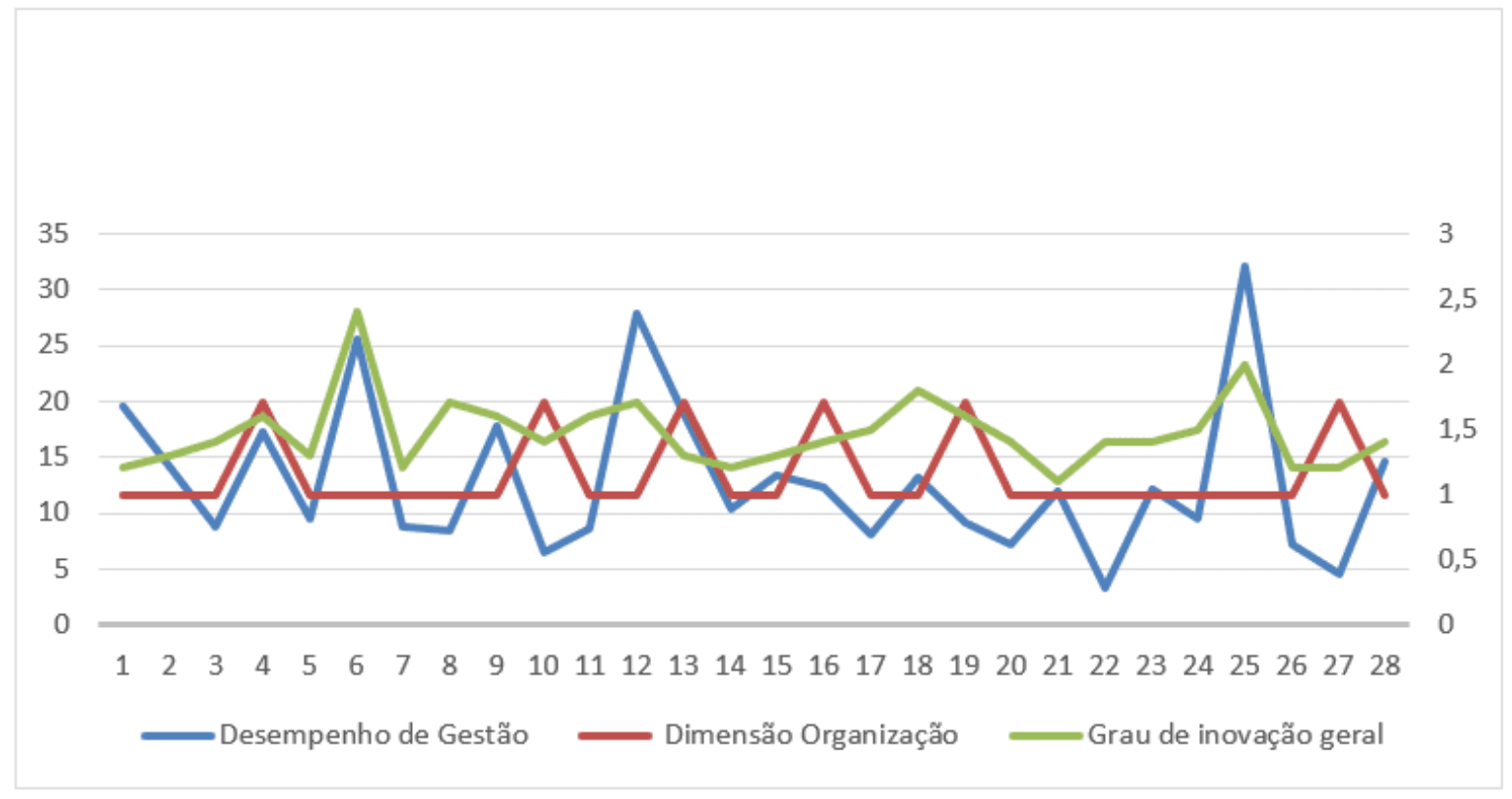

Fonte:

Elaborado

pelo

autor.

Nota: Foram utilizados percentuais nas três variáveis para efeito de comparação.

O Gráfico 1 mostra o cruzamento dos dados, mostrando a relação entre os aspectos abordados. Observa-se que os pontos altos, que são relacionados à gestão administrativa da empresa, se encontram também com níveis elevados do grau geral de inovação, permitindo inferir que quanto melhor a empresa está em relação ao desempenho de gestão, com uma melhor maturidade em gestão de processos, pessoas, clientes, obtém-se uma maior efetividade nas suas ações de inovação.

Em relação à Dimensão Organização observa-se que a curva apresenta comportamento mais próximo ao Desempenho de Gestão, que do grau de inovação geral. A explicação para tal fato, pode estar no fato de que o vínculo mais natural, para o segmento estudado, é que o Grau de Inovação Geral tem uma relação mais direta com o Desempenho da Gestão. As inovações realizadas nessa dimensão pouco têm se refletido no grau de inovação da empresa, da mesma forma que os pontos elevados se contrapõem ao desempenho de gestão de grande parte das empresas. Podendo inferir que as ações realizadas dentro dessa dimensão necessitam do aporte 
administrativo da empresa para sua melhor efetivação e consequentemente melhores resultados.

$\mathrm{Na}$ sequência apresentam-se algumas observações referentes ao modo como as empresas estão estruturadas, quais as parcerias estabelecidas e o papel e responsabilidades dos colaboradores, e as estratégias adotadas frente ao mercado.

Gráfico 2 - Reorganização

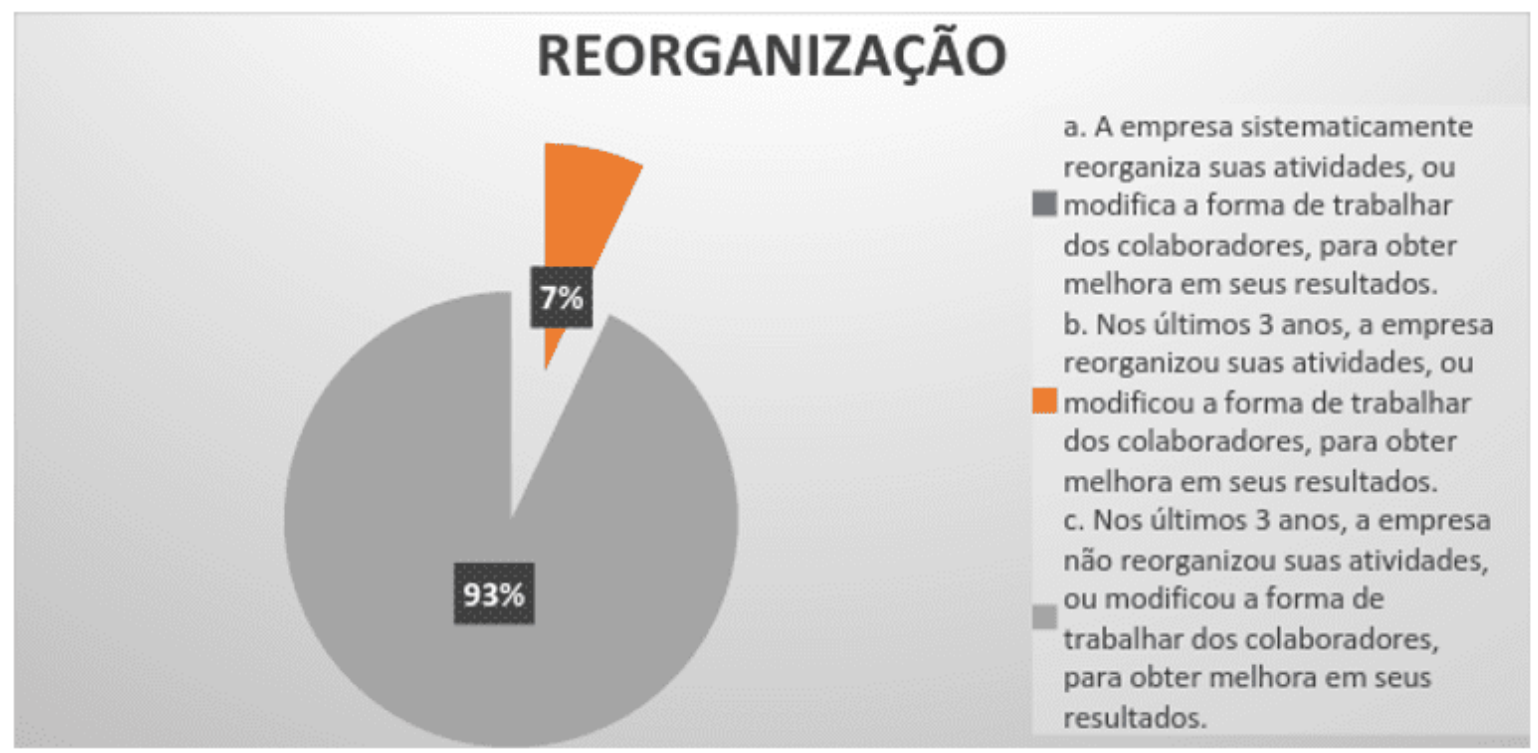

Fonte: Elaborado pelo autor.

$\mathrm{Na}$ questão que aborda a reorganização da empresa, 93\% das empresas não reorganizaram suas atividades, ou a forma de trabalhar dos colaboradores, para obter melhoria em seus resultados. Ou seja, a empresa não mudou sua estrutura para atender ou melhorar o seu atendimento diante das mudanças e inovações no mercado, mantendo-se a forma de trabalhar e os mesmos processos durante os últimos anos, tendo somente $7 \%$ das empresas se ocupado desse aspecto, implementando alterações na organização da empresa. 
Gráfico 3 - Parcerias firmadas pelas MPE

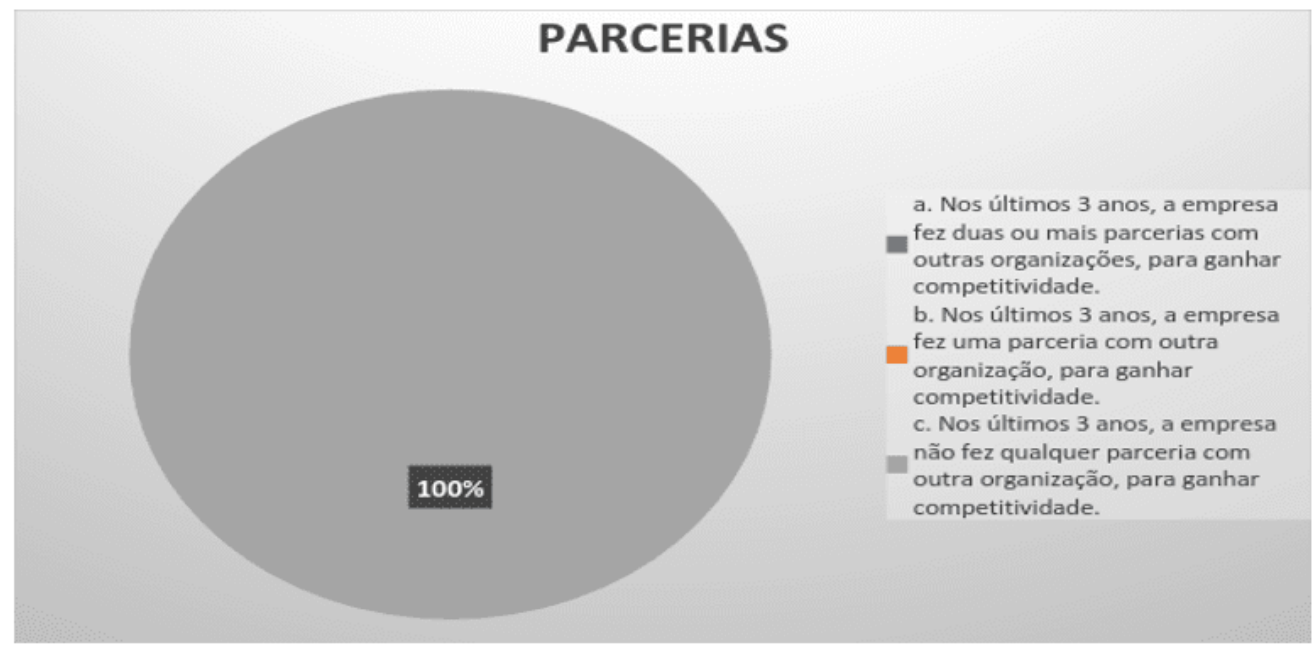

Fonte: Elaborado pelo autor.

No caso das parcerias o resultado verificado nesta pesquisa parece refletir uma característica desse tipo de segmento produtivo, extremamente centralizado e focado nas atividades do próprio negócio. Quando questionados sobre as parcerias realizadas para ganhar competitividade comercial, 100\% não realizaram nenhuma parceria nos últimos anos. (Ver Gráfico 3)

Gráfico 4 - Estratégia Competitiva

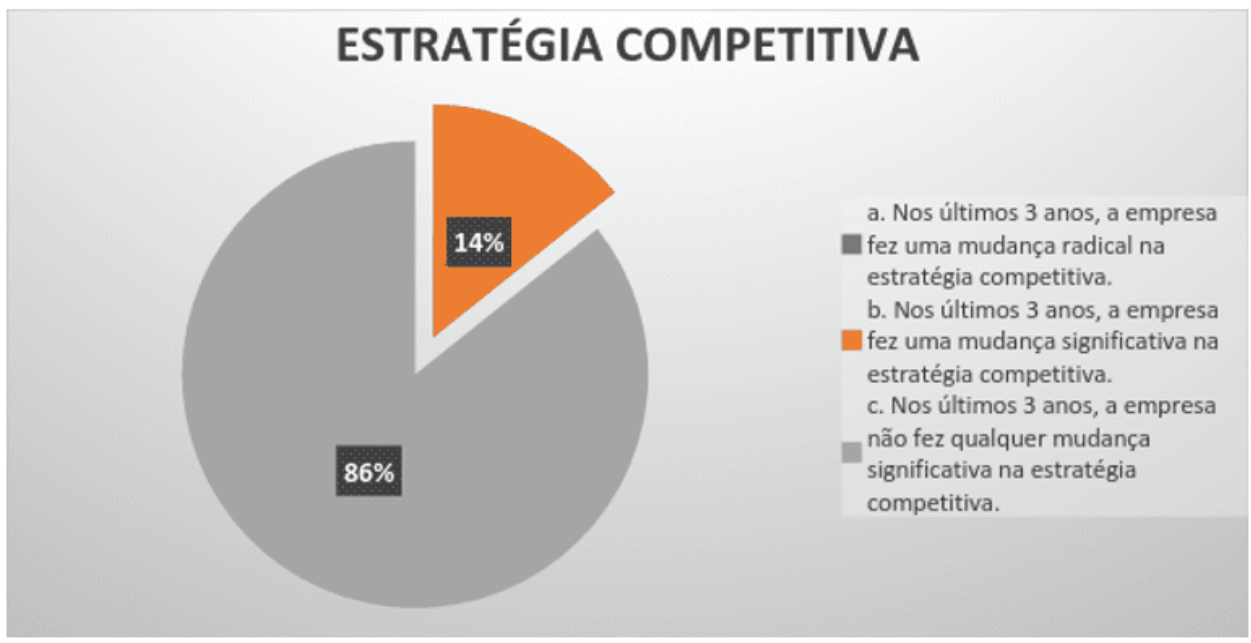

Fonte: Elaborada pelo autor 
Quando foram analisadas as estratégias competitivas adotadas, verificou-se que nos últimos 3 anos, $86 \%$ das empresas não fizeram qualquer mudança significativa na sua estratégia competitiva e apenas $14 \%$ consideram ter feito alguma alteração estratégica.

O resumo dos dados obtidos é indicativo dos graves problemas enfrentados pelas MPE aqui estudadas. É fato que nas dimensões estudadas existem lacunas que demandarão tempo, investimento e uma forte mudança cultural de parte dos empresários. Ações voltadas para elaboração e adequação do planejamento estratégico permitem a essas empresas uma melhor estruturação, idealização e construção do caminho a ser percorrido, traçando planos, metas e objetos que nortearam todos os processos da empresa.

A experiência vivida nas atividades desenvolvidas nessas empresas, com objetivo de trazer essa análise para o empresário, demonstra fatores que podem ser impeditivos para efetividade desse processo como a desmotivação do empresário, falta de visão de futuro do negócio e principalmente a falta de visão de mercado e gestão, que faz com que grande parte dos empresários estejam mais ativos no operacional da empresa do que no gerenciamento estratégico das mesmas.

\section{CONSIDERAÇÕES FINAIS}

As características da estrutura organizacional podem refletir diretamente no processo interno de inovação da empresa, partindo da premissa de que a inovação pode ser resultante do seu próprio processo. As formas de relacionamento interno e o padrão de execução das atividades da organização definem o ambiente propício a ambiência inovadora.

A teoria indica que os padrões adotados pela organização no ambiente de trabalho definem sua flexibilidade em relação ao mercado. Estruturas rígidas com ausência ou pouca comunicação entre os setores tornam o processo rígido com pouca abertura a mudanças e melhorias. 
Nesses termos, os resultados alcançados pela pesquisa demonstram a pouca flexibilidade e o baixo nível de iniciativa dessas empresas em relação à melhoria dos processos produtivos da empresa, sejam ele internos como demonstrado no gráfico 2 , no qual somente $7 \%$ das empresas buscam reorganizar ou modificar a forma de trabalho para alcançar novos patamares nos resultados empresarias. Assim como nos processos externos, não há busca por parcerias com outras organizações visando maior competitividade, esta pode ser visualizada no gráfico 3. Por fim, poucas mudanças nas estratégias competitivas adotadas, como demonstrado no gráfico 4 .

Relacionando esses dados com o desempenho de gestão dessas empresas, obtidos no Diagnóstico MPE, observa-se o pouco desempenho dessas empresas em relação à estruturação administrativa, tendo um baixo desempenho quando comparado a atual estrutura de trabalho, com ausência de processos definidos, alta centralização de atividades na figura dos empresários e pouca participação e comunicação com os colaboradores na melhoria e avaliação dos processos internos. Visualizando o grau de inovação geral da empresa observa-se que a dimensão Organização tem resultados pouco expressivos, demonstrando que poucas inovações têm sido feitas em relação a esse aspecto.

Quando observamos as empresas a partir dos parâmetros aqui analisados, com o tipo de estrutura e forma de trabalho atualmente adotados pelas organizações frente ao mercado - e também frente ao ambiente interno de trabalho, processos e organização - é possível constatar uma realidade caracterizada por atividades centralizadas que dão pouca abertura a mudanças e melhorias nos resultados empresarias.

\section{REFERÊNCIAS}

BREWS, P. J.; e TUCCI, C. L. "Exploring the Structural Effects of Internetworking". Strategic Management Journal, 429-452 p., 2004.

GEM. Empreendedorismo no Brasil, 2015. Disponível em: www.bibliotecas.sebrae.com.br/chronus/ARQUIVOS_CHRONUS/bds/bds.nsf/48261 71de33895ae2aa12cafe998c0a5/\$File/7347.pdf . Acesso em 29 de jun, 2017. 
HANSEN, M. T.; e NOHRIA, N. "How to Build Collaborative Advantage". MIT Sloan Management Review, 22-31p., 2004.

MARX, R.: Trabalho em grupos e autonomia como instrumentos de competição. São Paulo: Atlas, 1997.

MENGUC, B; Auh, S. Development and Return on Execution of Product Innovation Capabilities: The Role of Organizational Structure. Industrial Marketing Management, 2009.

NEGANO et al. O contexto Organizacional como aporte a inovação: um viés comparativo de casos em empresas brasileiras . Gest. Prod., São Carlos, 2014, v. 21, n. $3, \quad$ p. 477-490, Disponível em http://www.scielo.br/pdf/gp/v21n3/v21n3a03.pdf Acesso em 29 de jun. de 2017.

OLIVEIRA, Djalma de Pinho Rebouças de. Estrutura organizacional: uma abordagem para resultados e competitividade. São Paulo: Atlas, 2006.

OSTROFF, F. The Horizontal Organization: what the organization of the future actually looks like and how it delivers value to customers. USA: Oxford University Press, 1999.

OZSOMER, A.; CALANTONE, R. J.; Di BENEDETTO, A. "What Makes Firms More Innovative? A Look at Organizational and Environmental Factors”. Journal of Business \& Industrial Marketing,1997.

SACOMANO NETO, Mario; e ESCRIVÃO FILHO, Edmundo. Estrutura Organizacional e equipes de trabalho: estudo da mudança organizacional em quatro grandes empresas industriais.Gest. Prod. vol.7 no.2 São Carlos Aug. 2000 Disponível em http://www.scielo.br/scielo.php?script=sci_arttext\&pid=S0104-

530X2000000200004 Acesso em 15 de jun. de 2017.

SEVERO, Eliana Andrea; CRUZ, Marcia Rohr; DORION, Eric; GUIMARAES, Julio Cesar Ferro de; PEREIRA, Adrieli Alves. "Estrutura Organizacional das empresas inovadoras no Brasil." Espacios, Vol 33 (1) 2012, pag. 5. Disponível em 
http://www.revistaespacios.com/a12v33n11/12331105.html . Acesso em 14 de ago. de 2017.

SEBRAE, Micro e pequenas empresas geram 27\% do PIB do Brasil, Disponível em: https://www.sebrae.com.br/sites/PortalSebrae/ufs/mt/noticias/micro-e-pequenasempresas-geram-27-do-pib-dobrasil,ad0fc70646467410VgnVCM2000003c74010aRCRD. Acesso em 29 de jun, 2017.

TIDD, J., Bessant J., \& Pavitt K. Managing innovation: Integratingtechnological, market and organizational change: Scotprint, 2005.

\section{APÊNDICE - REFERÊNCIAS DE NOTA DE RODAPÉ}

3. Micro e pequenas empresas geram $27 \%$ do PIB do Brasil. 24/07/2014. In https://www.sebrae.com.br/sites/PortalSebrae/ufs/mt/noticias/micro-e-pequenasempresas-geram-27-do-pib-dobrasil,ad0fc70646467410VgnVCM2000003c74010aRCRD. (Acessado em 29.06.2017)

4. GEM. Empreendedorismo no Brasil. 2015. In http://www.bibliotecas.sebrae.com.br/chronus/ARQUIVOS_CHRONUS/bds/bds.nsf/4 826171de33895ae2aa12cafe998c0a5/\$File/7347.pdf. (Acessado em 29.06.2017)

5. O valor atribuído à empresa varia de 1 a 5 , de forma que quando a empresa obtém 1 considera-se pouco inovadora em relação ao aspecto abordado; 3 quando há algum investimento de inovação na área; e quando a nota é 5 a empresa é considerada totalmente inovadora em relação a determinado aspecto.

Enviado: Abril, 2020.

Aprovado: Abril, 2020. 